\title{
Mucosal biopsy shows immunologic changes of the colon in patients with early MS
}

\section{OPEN}

Adrian Mathias Moser, MD*

Walter Spindelboeck, MD*

Heimo Strohmaier, PhD Christian Enzinger, MD

Thomas Gattringer, MD Siegrid Fuchs, MD

Franz Fazekas, MD Gregor Gorkiewicz, MD Philipp Wurm, MSc Christoph Högenauer, MD

Michael Khalil, MD, PhD

Correspondence to Prof. Högenauer: christoph.hoegenauer@ medunigraz.at or Prof. Khalil: michael.khali@@medunigraz.at

Supplemental data at Neurology.org/nn

\section{ABSTRACT}

Objective: To investigate immune cells of the colonic mucosa and fecal short-chain fatty acids (SCFAs) in treatment-naive patients with a clinically isolated syndrome (CIS) or early relapsing MS.

Methods: In this cross-sectional proof-of-concept study, we obtained mucosal specimens during ileocolonoscopy from 15 untreated patients with CIS/MS and 10 controls. Mucosal immune cells were analyzed by FACS, and gas chromatography-mass spectrometry measurements of stool samples served to determine SCFA.

Results: The number of total dendritic cells (DCs), CD103+ tolerogenic DCs, and CD4+25+127regulatory $T$ cells (Tregs) was significantly reduced in the distal colon of patients with CIS/MS compared with controls, whereas we found no differences in the proximal colon. The patients' fecal samples also showed a substantially lower content of SCFA and especially lower levels of butyrate and acetate.

Conclusions: Our findings indicate a disturbed homeostasis of colonic DCs and Tregs in patients with MS which could be associated with colonic SCFA depletion. Although not implying causality, these findings confirm parallel abnormalities of the gut in MS and warrant further research if modulation of the colonic SCFA profile or the colonic Treg pool can serve to modify the course of MS. Neurol Neuroimmunol Neuroinflamm 2017;4:e362; doi: 10.1212/NXI.0000000000000362

\section{GLOSSARY}

CIS = clinically isolated syndrome; CNS = central nervous system; DC = dendritic cell; EAE = experimental autoimmune encephalomyelitis; EDSS = Expanded Disability Status Scale; EI = electron impact; $\mathbf{F C S}=$ fetal calf serum; FMO = fluorescence minus one; GC-EI/MS = gas chromatography-electron impact-mass spectrometry; HBSS = Hanks balanced salt solution; HPLC = high-performance liquid chromatography; IQR = interquartile range; IRB = institutional review board; LPDC = lamina propria DC; PEG = polyethylene glycol; RPMI = Roswell Park Memorial Institute; SCFA = short-chain fatty acid; Tregs $=$ regulatory $\mathrm{T}$ cell.

MS is a complex immune-mediated disease that is believed to arise in genetically susceptible individuals together with environmental factors such as viral infections, vitamin D deficiency, or smoking that promote or may even trigger autoimmunity. ${ }^{1-3}$ More recently, there have also been speculations on an important role of the gut in this process. ${ }^{4}$ Dysregulation of the gut microbiome may induce autoimmune responses at different sites, including the central nervous system (CNS). ${ }^{5-8}$

These insights are mainly derived from animal models of MS. Studies in experimental autoimmune encephalomyelitis (EAE) in mice showed that alterations in the gut microbiome induced by dietetic modifications to antibiotic ablation were associated with immunologic changes and influenced the severity of the disease. ${ }^{5,9}$ In this process, intestinal dendritic cells (DCs) appear to play a critical role as they act as antigen-presenting cells and are crucial in maintaining immune tolerance by interaction with numerous intestinal antigens. ${ }^{10}$ Lamina

\footnotetext{
*These authors contributed equally to this work.

From the Department of Internal Medicine (A.M.M., W.S., C.H.), Division of Gastroenterology and Hepatology, Theodor Escherich Laboratory for Microbiome Research (A.M.M., W.S., G.G., P.W., C.H.), Center for Medical Research (H.S.), Department of Neurology (C.E., T.G., S.F., F.F., M.K.), and Institute of Pathology (G.G., P.W.), Medical University of Graz, Austria.

Funding information and disclosures are provided at the end of the article. Go to Neurology.org/nn for full disclosure forms. The Article Processing Charge was funded by the authors.

This is an open access article distributed under the terms of the Creative Commons Attribution-NonCommercial-NoDerivatives License 4.0 (CC BY-NC-ND), which permits downloading and sharing the work provided it is properly cited. The work cannot be changed in any way or used commercially without permission from the journal.
} 
Figure 1 FACS analysis of colonic mucosal DCs and Tregs

A

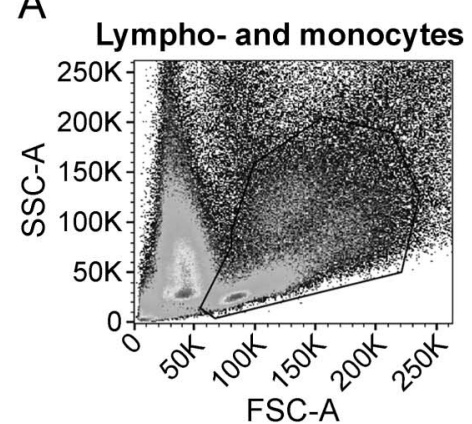

B

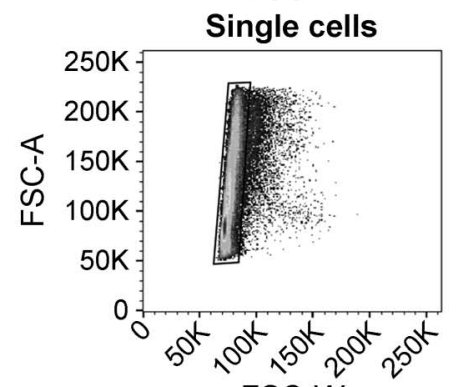

FSC-W
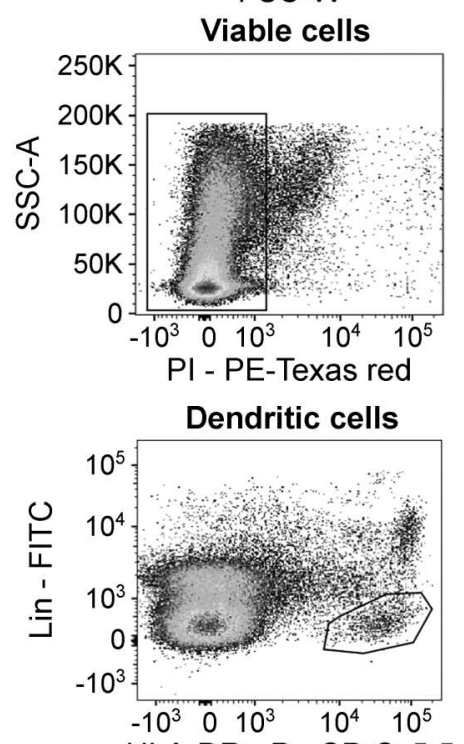

HLA-DR - PerCP-Cy5.5

CD103+ dendritic cells

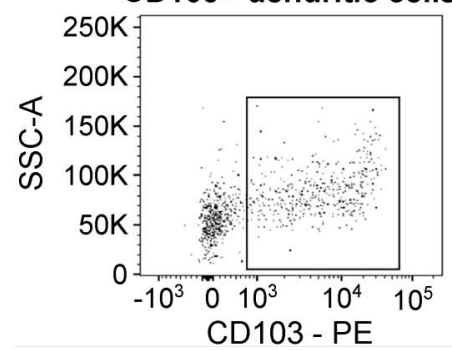

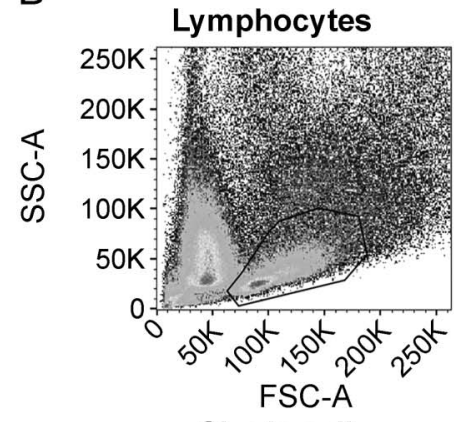

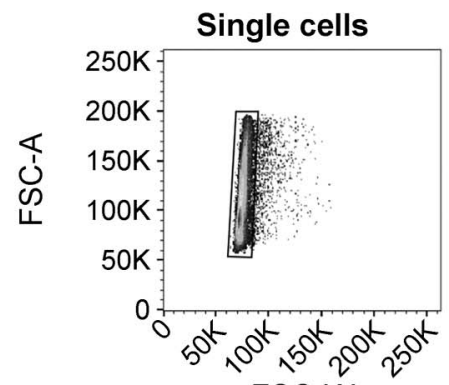

FSC-W
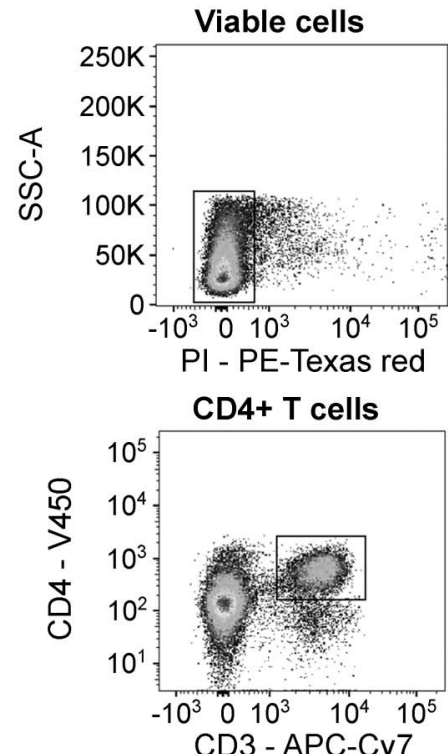

CD3 - APC-Cy 7
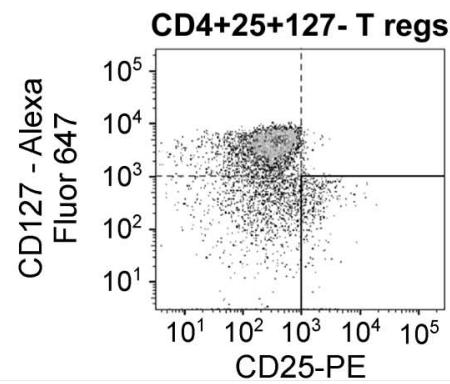

Colonic specimens were obtained separately from the proximal and distal colon, and lamina propria mononuclear cells were isolated. (A) DCs were identified as live single cells that stain negatively for lin (lineage) 1 markers (CD3, CD14, CD16, CD19, CD20, CD56, and CD34) and positively for HLA-DR. CD103-positive DCs were gated out of the DC population. (B) Tregs were identified as live single cells that stain positively for CD3, CD4, and CD25 markers and negatively for CD127. DC = dendritic cell; FACS = fluorescence-activated cell sorting; Treg $=$ regulatory $T$ cells.

propria DCs (LPDCs) transport bacterial antigens and products to the mesenteric lymph nodes, where the balance between tolerance of the commensal microbiota and surveillance of invading pathogenic bacteria is tightly regulated. ${ }^{11,12}$ This critical function is further underlined by the ability of DCs to induce regulatory $\mathrm{T}$ cells (Tregs) and therefore maintain or establish immune tolerance. ${ }^{13}$ In particular, the CD103+ DC subtype is vital for the differentiation of Tregs, which is believed to exhibit tolerogenic properties in mice and humans. ${ }^{14,15}$ Tregs have been implicated in the protection against CNS demyelination in mice, and their expansion has been reported to occur in gut mucosa and draining lymph nodes of EAE-protected germ-free mice. ${ }^{16,17}$

All these processes are tightly regulated by a complex interplay of the gut flora, dietary intake, and mucosal immune cells. ${ }^{5,9,18}$ In this context, short-chain fatty acids (SCFAs) have been suggested to play a pivotal role, and murine CNS demyelination was inhibited by peroral treatment with propionate through expansion of intestinal Tregs. ${ }^{19}$ Other studies underline the role of SCFAs, especially acetate, butyrate, and propionate in mediating regulatory intestinal immune responses. Treg homeostasis has, thereby, been shown to be dependent on the presence and extent of SCFAs produced by commensal bacteria in mice. Moreover, SCFAs endow DCs with an enhanced ability to induce the differentiation of Tregs. ${ }^{18,20,21}$ Recently, oral propionate administration also resulted in expanded peripheral Treg counts in patients with MS. ${ }^{22}$

On the basis of these data, we hypothesized that corresponding changes in immune cells of the gut mucosa and in SCFAs should also be present in patients with MS. We speculated to find lower numbers of DCs, in particular CD103+ DCs in the colon mucosa of patients with MS, which might be associated with fewer Tregs. To minimize confounding influences, we focused on patients without diseasemodifying treatment in the early stage of MS.

METHODS Patients and controls. Between 2013 and 2014, we consecutively recruited patients from the MS outpatient clinic of the Department of Neurology, Medical University of Graz for this cross-sectional study who were interested in our research question including the results of a colonic biopsy. 
Inclusion criteria were as follows: (1) early MS as evidenced by a clinically isolated syndrome (CIS) suggestive of MS or relapsingremitting MS within the first year after diagnosis, ${ }^{23}$ (2) age between 18 and 60 years, and (3) informed consent. Exclusion criteria were as follows: (1) a known gastrointestinal pathology, (2) previous or ongoing disease-modifying treatment of MS, (3) evidence for a concomitant other autoimmune disease, (4) gastrointestinal infection during the last 2 months before endoscopy, (5) a steroid pulse $<30$ days before endoscopy, (6) antibiotic therapy during the last month before endoscopy, (7) clinically relevant coagulopathy, (8) Expanded Disability Status Scale (EDSS) $\geq 7$, (9) severe infectious disease, (10) alcohol or drug abuse, and (11) history of a prior technically impossible colonoscopy. As controls, we included healthy individuals (recruited between 2013 and 2014 from the Department of Gastroenterology and Hepatology, Medical University of Graz) meeting the following inclusion criteria: (1) age between 18 and 60 years, (2) screening colonoscopy for colorectal cancer due to age, positive family history, or patient request, and (3) informed consent. The exclusion criteria were identical to those of the patients with CIS/ MS. None of the controls had signs of an acute illness or received any long-term medication.

Ileocolonoscopy and isolation of LP mononuclear cells. Ileocolonoscopy was performed with standard equipment (Olympus, Hamburg, Germany) in sedated subjects. Tissue specimens were obtained by forceps biopsy. Biopsies were separately taken from the proximal (cecum and ascending colon) and distal (descending and sigmoid colon) colon during the retraction of the colonoscope to investigate possible differences of colonic immune cells related to colonic compartments. ${ }^{24}$ Colonic biopsy specimens were immediately preserved in chilled Roswell Park Memorial Institute (RPMI) medium (Sigma-Aldrich, St. Louis, MO; supplemented with penicillin, streptomycin, and amphotericin). Biopsies were washed once with calcium- and magnesiumfree Hanks balanced salt solution (HBSS) (Life Technologies, Vienna, Austria) and then incubated in calcium- and magnesiumfree HBSS containing $1 \mathrm{mM}$ dithiothreitol and $5 \mathrm{mM}$ EDTA at $37^{\circ} \mathrm{C}$ for 20 minutes with gentle agitation to remove mucus and epithelial cells. Following a brief wash with calcium- and magnesium-free HBSS, tissue was digested with $1 \mathrm{mg} / \mathrm{mL} \mathrm{Col}$ lagenase A (Roche, Basel, Switzerland) and $5 \mathrm{U} / \mathrm{mL}$ DNase I (Roche) in $\mathrm{HBSS}$ at $37^{\circ} \mathrm{C}$ for 60 minutes on a shaker and mechanically disrupted by gentle pipetting. Complete dissociation

\begin{tabular}{|c|c|c|c|c|}
\hline \multirow[t]{2}{*}{ Table } & \multicolumn{4}{|c|}{$\begin{array}{l}\text { Clinical and demographic data of } 15 \text { MS-p and } 10 \text { healthy controls (Ctrl) } \\
\text { included in the study }\end{array}$} \\
\hline & & MS-p $p^{a}$ & Ctrl & $p$ Value \\
\hline \multicolumn{2}{|c|}{ No. of patients (\% women) } & $15(53)$ & $10(40)$ & $N S^{b}$ \\
\hline \multicolumn{2}{|c|}{ Age at colonoscopy, y, mean (SD) } & $35(7)$ & $44(13)$ & $<0.05^{\mathrm{c}}$ \\
\hline \multicolumn{2}{|c|}{ Age at disease onset, $y$, mean (SD) } & $33(7)$ & NA & NA \\
\hline \multicolumn{2}{|c|}{ Disease duration at colonoscopy, mo, median (range) } & $7(4-29)$ & NA & NA \\
\hline \multicolumn{2}{|c|}{ EDSS at time of colonoscopy, median (range) } & $1.5(1.0-2.0)$ & NA & NA \\
\hline \multicolumn{2}{|c|}{$\begin{array}{l}\text { No. of patients with disease-modifying treatment } \\
\text { at colonoscopy (\%) }\end{array}$} & $0(0.0)$ & NA & NA \\
\hline
\end{tabular}

Abbreviations: $\mathrm{Ctrl}=$ control patients; EDSS = Expanded Disability Status Scale; MS-p = patients with MS; NA = not applicable; NS = not significant.

a The MS-p cohort consisted of 10 patients with clinically isolated syndromes and 5 patients with relapsing-remitting MS.

${ }^{\mathrm{b}}$ Fisher exact test.

${ }^{\mathrm{c}}$ Mann-Whitney $U$ test. was verified by visual inspection. After passing through a $70-\mu \mathrm{m}$ cell strainer, the released cells were washed twice with RPMI complete medium (containing 10\% fetal calf serum [FCS] and $1 \%$ penicillin/streptomycin) and finally resuspended in RPMI complete medium. The cell suspension was kept on ice until further analysis.

Flow cytometry. Mucosal immune cell subsets were characterized by FACS analysis as previously described (figure 1). ${ }^{25,26}$ The cell suspension was washed once with staining buffer (phosphatebuffered saline containing 3\% FCS and 2 mM EDTA), and the cells were stained with $100 \mu \mathrm{L}$ staining buffer for 20 minutes at room temperature in the dark. For enumeration of LPDCs, directly labeled monoclonal antibodies for the following markers were used: lin (lineage) 1-FITC (CD3, CD14, CD16, CD19, CD20, CD56, and CD34), HLA-DR-PerCP-Cy5.5, CD11cAPC, and CD103-PE. LPDCs were identified as lin1-/ HLADR + cells. For determination of Tregs, anti-CD3-APCCy7, anti-CD4-V450, anti-CD8-FITC, anti-CD25-PE, and anti-CD127-Alexa Fluor 647 antibodies were used. With the exception of CD103-PE (eBioscience, San Diego, CA), all antibodies were purchased from BD Bioscience (San Jose, CA). FMO (fluorescence minus one) controls were used to set the boundaries for gating of positively stained cells. After the staining reaction, the cells were washed once with staining buffer and resuspended in $100 \mu \mathrm{L}$ staining buffer. For the exclusion of dead cells, propidium iodide was added to the samples immediately before acquisition on an LSR II (BD Bioscience) flow cytometer. The data files were analyzed using FlowJo (FlowJo, LLC, Ashland, OR) software.

Gas chromatography-electron impact-mass spectrometry (GC-EI/MS) of SCFAs. SCFAs previously investigated in animal studies to study cellular immune reactions (acetic acid, propionic acid, isobutyric acid, butyric acid, isovaleric acid, and valeric acid) were extracted from stool frozen at $-80^{\circ} \mathrm{C} .{ }^{18-20}$ SCFA concentrations were measured by GC-MS equipped with a polyethylene

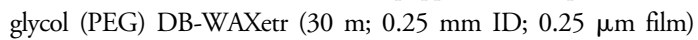
column. SCFAs were extracted from feces by sequential addition of $1 \mathrm{~mL}$ phosphoric acid $(0.5 \%)$ and $1 \mathrm{~mL}$ methyl tert-butyl ether, 10 minutes shaking, 10 minutes centrifugation, and removal of the upper organic layer. Before extraction, $100 \mathrm{nmol}$ of D-acetic acid, D-propionic acid, D-butyric acid, and D-valeric acid were added as internal standards. Calibration curves by stable isotope dilution were performed from 0.1 to $2,000 \mu \mathrm{M}$ for acetic acid, propionic acid, isobutyric acid, butyric acid, isovaleric acid, and valeric acid. A 7890B/5977A MSD GC-MS (Agilent Technologies, Waldbronn, Germany) equipped with a PEG DB-WAXetr (30 m; $0.25 \mathrm{~mm}$ ID; $0.25 \mu \mathrm{m}$ film) column was used. Helium was used as carrier gas at $1.3 \mathrm{~mL} / \mathrm{min}$ in splitless mode at $250^{\circ} \mathrm{C}$ injector temperature. The initial oven temperature of $60^{\circ} \mathrm{C}$ was held for 2 minutes, and then the temperature first was ramped up to $150^{\circ} \mathrm{C}$ at a rate of $15^{\circ} \mathrm{C} / \mathrm{min}$. This was followed by a ramp of $5^{\circ} \mathrm{C} / \mathrm{min}$ up to $170^{\circ} \mathrm{C}$ and $20^{\circ} \mathrm{C} /$ min up to $250^{\circ} \mathrm{C}$, where the temperature was held for another 2 minutes. The mass spectrometer was run in EI mode, where the fatty acids were detected in selected ion monitoring mode on $\mathrm{m} / \mathrm{z}$ $60,63,73,74,76,79$, and 80 . The source temperature was set to $250^{\circ} \mathrm{C}$, and the transfer line temperature was $280^{\circ} \mathrm{C}$. Data analysis was performed by MassHunter (Agilent Technologies).

Statistics. Statistical analyses were performed using SPSS 22 (IBM Corp., Armonk, NY) and GraphPad Prism (GraphPad Software, Inc., La Jolla, CA). Values are presented as number (\%), mean (SD), or median (interquartile range [IQR]) as appropriate. For the comparison of categorical variables, we applied Fisher exact test. Group differences of continuous variables were determined by Mann-Whitney $U$ test or $t$ test depending on 
Figure 2 Reduction of mucosal DCs in the distal colon of MS-p
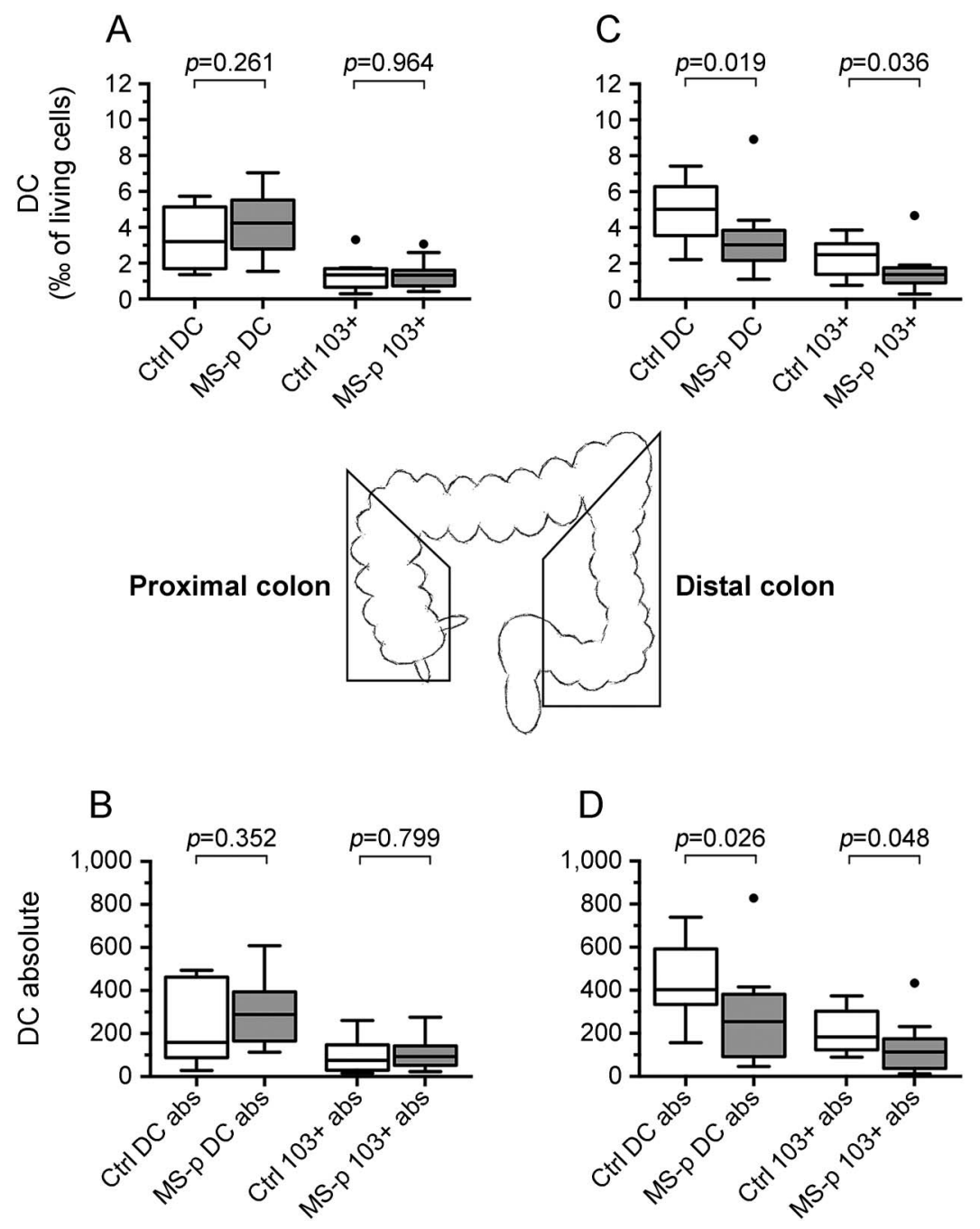

DC numbers from the proximal ( $A$ and $B$ ) and distal ( $C$ and $D)$ colon, see central scheme. ( $A$ and B) No significant differences in the number of total and CD103+ DCs were found in the proximal colon of MS-p compared with controls (Ctrl). (C and D) In the distal colon, significant reductions of total and CD103+ DCs were observed in MS-p compared with Ctrl (total DCs: 3.0 [2.2-3.8] vs 5.0 [3.6-6.3], $p=0.019$ [\% of living cells] and 255 [93-381] vs 404 [335592], $p=0.026$ [absolute numbers]; CD103+ DCs: 1.4 [0.9-1.8] vs $2.5[1.4-3.1], p=0.036$ [\% of living cells] and 114 [38-174] vs 183 [124-303], $p=0.048$ [absolute numbers]) (median [Q1-Q3]; Mann-Whitney $U$ test or $t$ test to compare non-Gaussian and Gaussian variables. Boxplots according to Tukey). DC = dendritic cell; MS-p = patients with MS.

non-Gaussian and Gaussian data distribution. Boxplots are depicted according to Tukey. Correlation analyses were performed using Spearman rank correlation coefficient $(\rho)$.

Standard protocol approvals, registrations, and patient consents. All individuals signed informed consent before study inclusion. The study was approved by the local institutional review board (IRB no. IRB00002556), vote 25-287 ex 12/13

RESULTS Patients and controls. Over a period of 10 months, we screened consecutive patients for the respective inclusion and exclusion criteria, and 15 (10 with a CIS) consented to the study. Their mean age was 35 (SD 7) years. Eight of the fifteen patients were women, and the interval between first symptoms and colonoscopy was 0.5 years. Median EDSS ${ }^{27}$ was 2 (IQR 1.0-2.0) at the time of colonoscopy. As controls, we included 10 healthy individuals, with a mean age of 44 (SD 13) years, who were scheduled for screening colonoscopy during the same period. This group consisted of 6 men and 4 women (table).

DCs and Tregs in the colon mucosa. Using FACS analysis, we explored the number of total DCs (defined as lin1-/HLADR + cells), CD103+ DCs, and CD4+25+127-Tregs in the mucosa of the proximal and distal colon. No differences between patients with CIS/MS and controls were observed in the proximal colon (figure 2, A and B). Patients with CIS/ MS had significantly fewer overall DCs and CD103+ DCs in the distal colon compared with controls (total DCs: 3.0 [2.2-3.8] vs 5.0 [3.6-6.3], $p=0.019$ [\%o of living cells] and 255 [93-381] vs 404 [335592], $p=0.026$ [absolute numbers]; CD103+ DCs: $1.4[0.9-1.8]$ vs $2.5[1.4-3.1], p=0.036[\%$ of living cells] and 114 [38-174] vs 183 [124-303], $p=0.048$ [absolute numbers], figure 2, C and D).

Furthermore, significant reductions of Tregs in patients with CIS/MS were likewise only observed in the distal colon (Tregs: 3.1 [1.3-3.7] vs 4.7 [3.4-6.1], $p=0.032[\%$ of living cells] and 153 [83-205] vs 226 [136-510], $p=0.023$ [absolute numbers], figure 3, A-D). Levels of $\mathrm{CD}^{+}, \mathrm{CD}^{+}$ $\mathrm{T}$ cells (figure e-1, A-D at Neurology.org/nn), and natural killer cells (figure e-2, A-D) did not differ between patients with CIS/MS and controls.

As we observed a significant age difference between patients with CIS/MS and controls, we calculated the correlations between age and total DCs, CD103+ DCs, and Tregs. Significant (negative) correlations were observed between age and Tregs in both compartments (proximal Tregs: $p=0.048, \rho=-0.461$; distal Tregs: $p=0.029, \rho=-0.489$, figure e-3, A-C). Correlations between age and total DCs (proximal: $p=0.949$, $\rho=-0.013$; distal: $p=0.155, \rho=0.299)$ and CD103+DCs (proximal: $p=0.668, \rho=-0.092$; distal: $p=0.093, \rho=0.351$ ) remained not significant.

SCFA levels in fecal samples. High-performance liquid chromatography (HPLC) was used to assess levels of SCFAs in fecal samples obtained at the time of ileocolonoscopy and showed that total SCFA content as well as acetate and butyrate levels of patients with CIS/MS were significantly reduced by $50 \%-60 \%$ compared with control stools. Propionate and valerate were also reduced in patients with CIS/MS, but this difference did not reach statistical significance (figure 4). The order of absolute abundances of single SCFAs was similar in patients with CIS/MS and controls (acetate $>$ propionate $>$ butyrate $>$ valerate $>$ isovalerate $>$ isobutyrate). 
Figure 3 Reduction of mucosal Tregs in the distal colon of MS-p
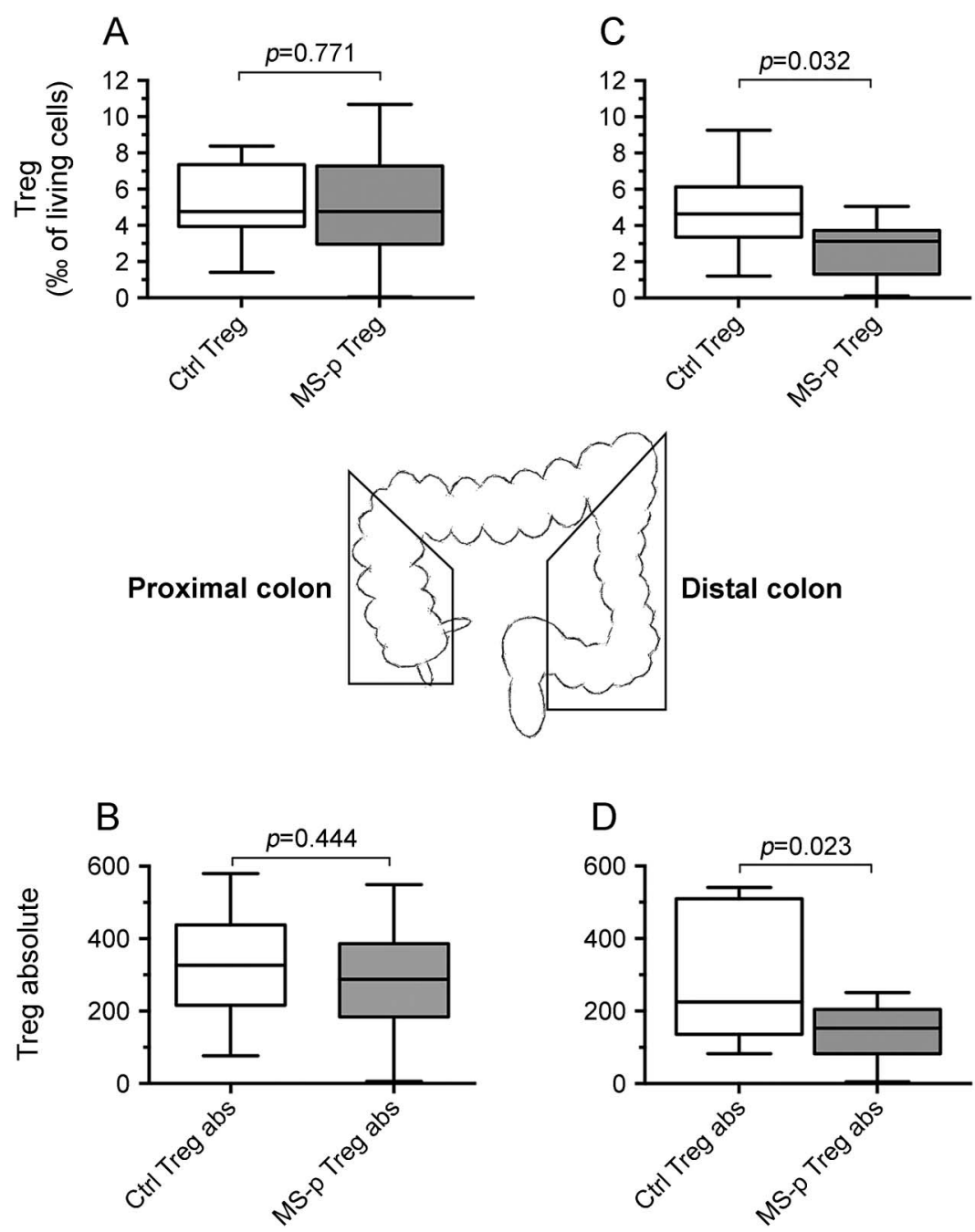

Treg numbers from the proximal ( $A$ and $B$ ) and distal ( $C$ and $D)$ colon, see central scheme. (A and $B$ ) No significant differences in the number of Tregs were found in the proximal colon of MS-p compared with controls (Ctrl). (C and D) In the distal colon, significant reductions of Tregs were observed in MS-p compared with Ctrl (Tregs: 3.1 [1.3-3.7] vs 4.7 [3.4-6.1], $p=0.032[\%$ of living cells] and 153 [83-205] vs 226 [136-510], $p=0.023$ [absolute numbers]) (median [Q1-Q3]; Mann-Whitney $U$ test or $t$ test to compare non-Gaussian and Gaussian variables. Boxplots according to Tukey). MS- $p=$ patients with MS; Treg = regulatory T cells. and distal colon have been shown to differ in embryologic origin, gene-expression patterns, genemethylation status, microbiota load, and microbiota metabolic activity (e.g., SCFAs). ${ }^{29-31}$ In addition, mucosal DC subsets differ between the proximal and distal colon of healthy individuals. ${ }^{24}$ Altogether, these findings suggest a concept of colonic immune compartmentalization which may well explain our different observations in the proximal and distal colon. Although the causes of the observed regional differences are not clear, altered amounts of bacterial metabolites along the colon may be of relevance. ${ }^{31}$

We also found a decrease of the total SCFA content as well as of acetate and butyrate levels accompanied by trends toward lower levels of propionate and valerate in stools of early MS patients compared with controls. These observations were hitherto not made in humans and could suggest a concept where changes of mucosal immune cells may be linked to reduced levels of certain bacterial metabolites in the colon of patients with MS. Propionate has been shown to be the most potent Treg inducer in vitro, and oral gavage ameliorated CNS demyelination in mice. ${ }^{19}$ Propionate levels were lower in our patients with MS although not to a significant extent. However, this may have been due to the small sample size. Otherwise we observed significantly lower levels of acetate and butyrate in patients with MS than controls, which have been shown to potently induce colonic Tregs in mice as well. It could, therefore, be speculated that their decrease may be of greater clinical relevance in patients with MS than that of propionate, although this interpretation again needs great caution because of the few individuals investigated. To what extent this reduction is a consequence of specific microbial alterations or of dietary intake is yet unclear. Of interest, food patterns compatible with western lifestyle have been proposed to increase the incidence of MS, and fecal microbiota disturbances have been reported to occur in patients with MS compared with healthy controls. ${ }^{32-34}$ In turn, adherence to a Mediterranean diet elevated butyrate, acetate, and propionate levels in healthy individuals. ${ }^{35}$ Thus, dietary factors may promote dysregulation of mucosal immune cells through an altered intestinal microenvironment. Diet, substrate availability, and synthesis capacities of bacteria may potentially contribute to the amounts of intestinal SCFAs, and therefore constitute potential explanations for the reduction of SCFAs in patients with MS. ${ }^{31}$ However, this certainly needs further investigation.

Our findings in humans also support immunologic models hitherto only described in animals with EAE, which postulated that luminal SCFA content impacts on the regulatory capacity of mucosal DCs and the formation of the colonic Treg pool. ${ }^{18,19,36}$ 

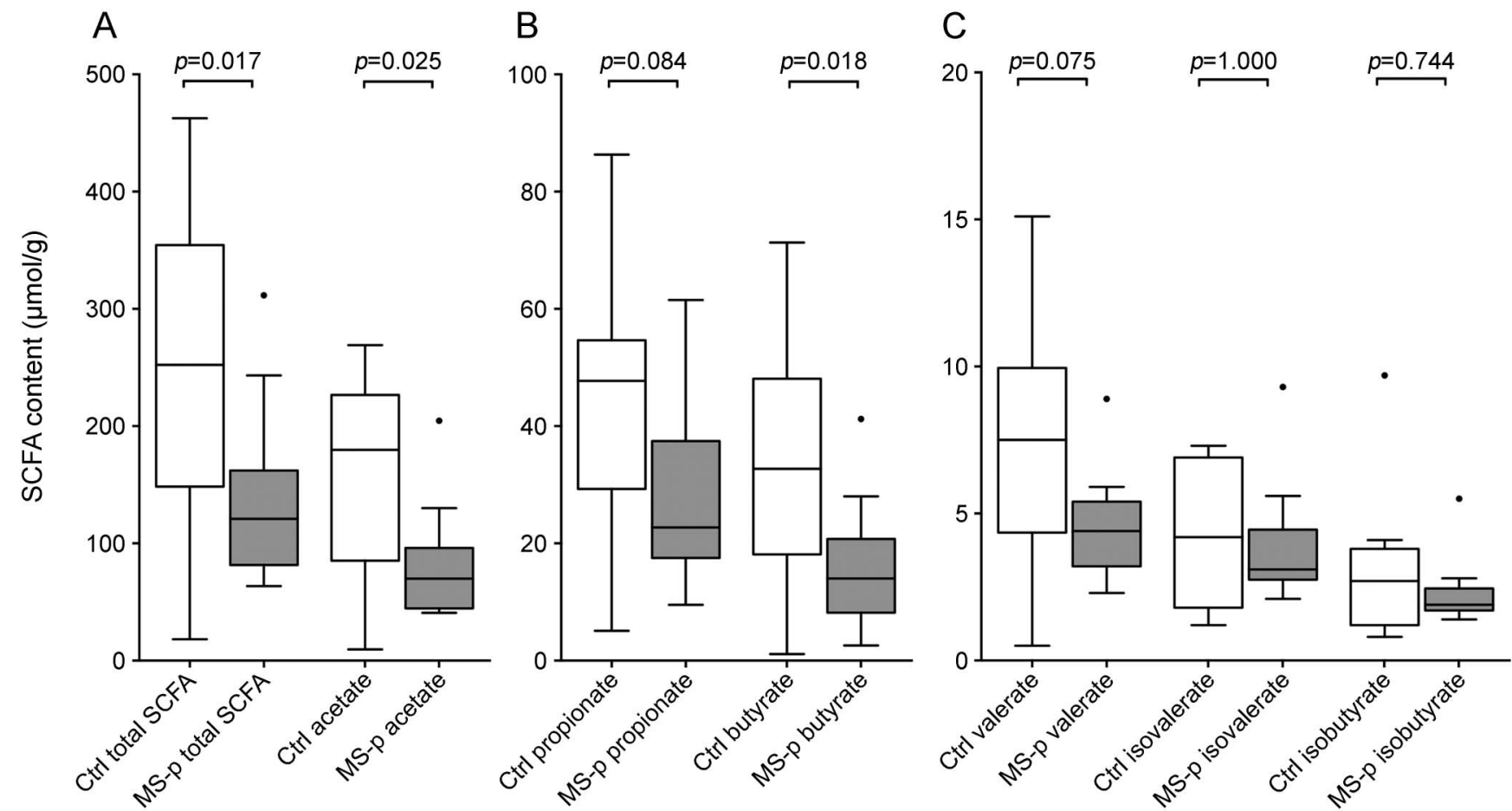

(A-C) Fecal samples were analyzed by HPLC. SCFA contents are shown in order of their absolute quantity in $\mu$ mol/g (total $>$ acetate $>$ propionate $>$ butyrate $>$ valerate $>$ isovalerate $>$ isobutyrate). A significant reduction in MS-p (gray) vs controls (white) was found in total SCFA (252 [148-354] vs 121 [82-162]; $p=0.017$ ), acetate (180 [85-227] vs 70 [45-96]; $p=0.025)$, and butyrate contents (33 [18-48] vs 14 [8-21]; $p=0.018)$. Trends were observed in propionate $(p=0.084)$ and valerate contents $(p=0.075)$ (median [Q1-Q3]; Mann-Whitney $U$ test or $t$ test to compare non-Gaussian and Gaussian variables. Boxplots according to Tukey). HPLC = high-performance liquid chromatography; MS-p = patients with MS; SCFA = short-chain fatty acid.

Based on our data, one may hypothesize that lower SCFA content (especially acetate and butyrate) together with a reduced number of total and tolerogenic DCs may trigger a quantitative impairment of Tregs in the distal colon of patients with MS. These alterations are also likely to impact on a systemic level, as changes in the lymphatic immune system in mice could be observed after manipulation of the intestinal ecosystem. Thereby, activation of CD103+ DCs in cervical lymph nodes played a major role in attenuating CNS autoimmunity. ${ }^{16}$ Of interest, a recent report provides evidence for the CNS lymphatic system communicating with deep cervical lymph nodes. ${ }^{37}$ Because the lymphatic system is known to communicate throughout the whole body, information from the intestinal lymphatic system may also reach the CNS. ${ }^{37,38}$ In this context, T cells have already been shown to gain autoreactive function in extracerebral tissues such as the lungs and to migrate to the CNS transgressing the blood-brain barrier. ${ }^{39}$ The concept of extracerebral immune-cell alterations at mucosal sites may, therefore, be supported by our data and warrants further mechanistic investigation regarding the gut in patients with MS.

In this study, we solely focused on patients with early MS and therefore we do not know if observed changes in the colonic mucosa may further increase with more advanced disease, which needs to be acknowledged as a limitation of the study. This study design also prohibited a more close matching of patients and controls. However, our analysis of the effect of age on Tregs indicates that the significantly higher age of controls should have led to an underestimation rather than an overestimation of observed differences. We also defined a large number of exclusion criteria to avoid any systematic bias. Nevertheless, participating individuals may not have been fully representational of patients with CIS/MS and healthy individuals in general, which needs to be acknowledged as another possible limitation. Our findings thus will need to be replicated by further studies. Future studies on a larger number of patients should also allow us to probe potential associations of immunologic changes in the colonic mucosa with clinical and radiologic findings. It is also important to stress that our findings in the colon of patients with CIS/MS cannot serve to establish a causal relationship with their CNS disease. The immunologic changes observed could also just mirror a more general immune dysregulation of such patients. Furthermore, a suggested interplay between the changes in immune cells of the distal colon and content in SCFAs has to remain speculative as our observations 
are based on cross-sectional data. These important points also need to be addressed in future studies.

Altogether, our findings extend and substantiate previous speculations on a disturbed immune milieu in the colon of patients with MS and support the possibility of a role of the colonic microenvironment in the immunopathogenesis of MS. Once confirmed, our observations could give rise to test if therapeutic interventions that modulate the colonic SCFA profile or the colonic Treg pool can modify the course of MS. ${ }^{40}$

\section{AUTHOR CONTRIBUTIONS}

A.M.M. and W.S. planned the study and experiments and analyzed data. A.M.M., W.S., M.K., and F.F. wrote the paper. C.H., M.K., F.F., S.F., and C.E supervised the study planning and implementation and gave scientific advices. H.S. performed immunologic analyses. T.G., M.K., C.E., F.F., and S.F. recruited patients. All authors were involved in the preparation of the manuscript and data discussion.

\section{ACKNOWLEDGMENT}

The authors thank Jennifer Ober for her efforts in performing FACS analyses and Harald Köfeler for his support regarding SCFA measurements. They acknowledge the support in endoscopic examinations by Elisabeth Krones, Patrizia K. Kump, and Andreas Eherer.

\section{STUDY FUNDING}

No targeted funding reported.

\section{DISCLOSURE}

A.M. Moser reports no disclosures. W. Spindelboeck received travel funding from AbbVie. H. Strohmaier reports no disclosures. C. Enzinger served on the scientific advisory board for Biogen-Idec, Bayer-Schering, Merck Serono, Novartis, and Teva Ratiopharm; received travel funding and speaker honoraria from Biogen-Idec, Teva-Aventis, Merck Serono, Bayer-Schering, and Novartis; consulted for Biogen-Idec, Novartis, Genzyme, Merck Serono, and Bayer-Schering; and received research support from Teva-Aventis, Biogen-Idec, and Merck Serono. T. Gattringer served on the scientific advisory board for Boehringer Ingelheim; received travel funding and speaker honoraria from Boehringer Ingelheim and Bayer Austria. S. Fuchs served on the scientific advisory board for Biogen-Idec, Novartis, Merck Serono, Genzyme, Roche, and Teva Ratiopharm and received speaker honoraria and/or travel funding from Biogen-Idec, Merck Serono, Genzyme, Roche, and Teva Ratiopharm. F. Fazekas served on the scientific advisory board for Biogen-Idec, Genzyme, Merck, Novartis, Perceptive Informatics, Roche, Teva Ratiopharm, Actelion, and University of Zurich; received travel funding and/or speaker honoraria from Almirall, Merck, Novartis, Roche, and Teva; served on the editorial board for Cerebrovascular Diseases, Journal of Neurology, Polish Journal of Neurology and Neurosurgery, Stroke, Swiss Archives of Neurology and Psychiatry, Multiple Sclerosis, European Stroke Journal, and Neurology ${ }^{\circledR}$; served on the speaker's bureau for Merck Serono; and received an unrestricted research grant to his institution by Teva Ratiopharm. G. Gorkiewicz is an editorial board member for Microbiome. P. Wurm and C. Högenauer report no disclosures. M. Khalil received travel funding and speaker honoraria from Bayer-Schering, Novartis, Genzyme, Merck Serono, Biogen, and Teva. Go to Neurology.org/nn for full disclosure forms.

Received January 3, 2017. Accepted in final form April 13, 2017.

\section{REFERENCES}

1. Ascherio A. Environmental factors in multiple sclerosis. Expert Rev Neurother 2013;13:3-9.

2. Dendrou CA, Fugger L, Friese MA. Immunopathology of multiple sclerosis. Nat Rev Immunol 2015;15:545-558.
3. Fitzgerald KC, Munger KL, Kochert K, et al. Association of vitamin D levels with multiple sclerosis activity and progression in patients receiving interferon beta- $1 \mathrm{~b}$. JAMA Neurol 2015;72:1458-1465.

4. Tremlett H, Fadrosh DW, Faruqi AA, et al. Gut microbiota composition and relapse risk in pediatric MS: a pilot study. J Neurol Sci 2016;363:153-157.

5. Ochoa-Reparaz J, Mielcarz DW, Begum-Haque S, Kasper LH. Gut, bugs, and brain: role of commensal bacteria in the control of central nervous system disease. Ann Neurol 2011;69:240-247.

6. Wekerle H, Berer K, Krishnamoorthy G. Remote controltriggering of brain autoimmune disease in the gut. Curr Opin Immunol 2013;25:683-689.

7. Hohlfeld R, Dornmair K, Meinl E, Wekerle H. The search for the target antigens of multiple sclerosis, part 1: autoreactive CD4 + T lymphocytes as pathogenic effectors and therapeutic targets. Lancet Neurol 2015;15:198209.

8. Hohlfeld R, Dornmair K, Meinl E, Wekerle H. The search for the target antigens of multiple sclerosis, part 2: CD8 $+\mathrm{T}$ cells, B cells, and antibodies in the focus of reverse-translational research. Lancet Neurol 2016;15: 317-331.

9. Joscelyn J, Kasper LH. Digesting the emerging role for the gut microbiome in central nervous system demyelination. Mult Scler 2014;20:1553-1559.

10. Scott CL, Aumeunier AM, Mowat AM. Intestinal $\mathrm{CD} 103+$ dendritic cells: master regulators of tolerance? Trends Immunol 2011;32:412-419.

11. Macpherson AJ, Uhr T. Induction of protective IgA by intestinal dendritic cells carrying commensal bacteria. Science 2004;303:1662-1665.

12. Voedisch S, Koenecke C, David S, et al. Mesenteric lymph nodes confine dendritic cell-mediated dissemination of Salmonella enterica serovar Typhimurium and limit systemic disease in mice. Infect Immun 2009;77: 3170-3180.

13. Worbs T, Bode U, Yan S, et al. Oral tolerance originates in the intestinal immune system and relies on antigen carriage by dendritic cells. J Exp Med 2006;203:519-527.

14. Yuan J, Zhang G, Yang X, Liu K, Wang F. Transplantation of allograft transforming growth factor-betal transfected CD103(+) lamina propria dendritic cells could effectively induce antigen-specific regulatory $\mathrm{T}$ cells in vivo. Transpl Proc 2013;45:3408-3413.

15. Worthington JJ, Czajkowska BI, Melton AC, Travis MA. Intestinal dendritic cells specialize to activate transforming growth factor-beta and induce Foxp3+ regulatory T cells via integrin $\alpha v \beta 8$. Gastroenterology 2011;141:1802-1812.

16. Ochoa-Reparaz J, Mielcarz DW, Wang Y, et al. A polysaccharide from the human commensal Bacteroides fragilis protects against CNS demyelinating disease. Mucosal Immunol 2010;3:487-495.

17. Lee YK, Menezes JS, Umesaki Y, Mazmanian SK. Proinflammatory T-cell responses to gut microbiota promote experimental autoimmune encephalomyelitis. Proc Natl Acad Sci USA 2011;108(suppl 1):4615-4622.

18. Arpaia N, Campbell C, Fan X, et al. Metabolites produced by commensal bacteria promote peripheral regulatory T-cell generation. Nature 2013;504:451-455.

19. Haghikia A, Jorg S, Duscha A, et al. Dietary fatty acids directly impact central nervous system autoimmunity via the small intestine. Immunity 2015;43:817-829. 
20. Furusawa Y, Obata Y, Fukuda S, et al. Commensal microbe-derived butyrate induces the differentiation of colonic regulatory T cells. Nature 2013;504:446-450.

21. Smith PM, Howitt MR, Panikov N, et al. The microbial metabolites, short-chain fatty acids, regulate colonic Treg cell homeostasis. Science 2013;341:569-573.

22. Haghikia A, Duscha A, Berg J, et al. Role of fatty acids in multiple sclerosis: therapeutic potential of propionic acid (P1.374). Neurology 2016;86.

23. Polman CH, Reingold SC, Banwell B, et al. Diagnostic criteria for multiple sclerosis: 2010 revisions to the McDonald criteria. Ann Neurol 2011;69:292-302.

24. Bernardo D, Durant L, Mann ER, et al. Chemokine (C-C motif) receptor 2 mediates dendritic cell recruitment to the human colon but is not responsible for differences observed in dendritic cell subsets, phenotype, and function between the proximal and distal colon. Cell Mol Gastroenterol Hepatol 2016;2:22-39.e5.

25. Mann ER, Landy JD, Bernardo D, et al. Intestinal dendritic cells: their role in intestinal inflammation, manipulation by the gut microbiota and differences between mice and men. Immunol Lett 2013;150:30-40.

26. Badami E, Sorini C, Coccia M, et al. Defective differentiation of regulatory FoxP3 $+\mathrm{T}$ cells by small-intestinal dendritic cells in patients with type 1 diabetes. Diabetes 2011;60:2120-2124.

27. Kurtzke JF. Rating neurologic impairment in multiple sclerosis: an expanded disability status scale (EDSS). Neurology 1983;33:1444-1452.

28. Abraham C, Cho JH. Inflammatory bowel disease. N Engl J Med 2009;361:2066-2078.

29. Glebov OK, Rodriguez LM, Nakahara K, et al. Distinguishing right from left colon by the pattern of gene expression. Cancer Epidemiol Biomarkers Prev 2003;12:755-762.
30. Kaz AM, Wong CJ, Dzieciatkowski S, Luo Y, Schoen RE, Grady WM. Patterns of DNA methylation in the normal colon vary by anatomical location, gender, and age. Epigenetics 2014;9:492-502.

31. Macfarlane S, Macfarlane GT. Regulation of short-chain fatty acid production. Proc Nutr Soc 2003;62:67-72.

32. Lauer K. Environmental risk factors in multiple sclerosis. Expert Rev Neurother 2010;10:421-440.

33. Chen J, Chia N, Kalari KR, et al. Multiple sclerosis patients have a distinct gut microbiota compared to healthy controls. Sci Rep 2016;6:28484.

34. Miyake S, Kim S, Suda W, et al. Dysbiosis in the gut microbiota of patients with multiple sclerosis, with a striking depletion of species belonging to clostridia XIVa and IV clusters. PLoS One 2015;10:e0137429.

35. De Filippis F, Pellegrini N, Vannini L, et al. High-level adherence to a Mediterranean diet beneficially impacts the gut microbiota and associated metabolome. Gut 2016;65: 1812-1821.

36. Berer K, Mues M, Koutrolos M, et al. Commensal microbiota and myelin autoantigen cooperate to trigger autoimmune demyelination. Nature 2011;479: $538-541$.

37. Louveau A, Smirnov I, Keyes TJ, et al. Structural and functional features of central nervous system lymphatic vessels. Nature 2015;523:337-341.

38. Delves PJ, Roitt IM. Roitt's Essential Immunology, 12th ed. Hoboken: Wiley-Blackwell; 2011.

39. Odoardi F, Sie C, Streyl K, et al. T cells become licensed in the lung to enter the central nervous system. Nature 2012;488:675-679.

40. Atarashi K, Tanoue T, Oshima K, et al. Treg induction by a rationally selected mixture of Clostridia strains from the human microbiota. Nature 2013;500:232-236. 


\section{Neurology \\ Neuroimmunology \& Neuroinflammation}

\section{Mucosal biopsy shows immunologic changes of the colon in patients with early MS Adrian Mathias Moser, Walter Spindelboeck, Heimo Strohmaier, et al. \\ Neurol Neuroimmunol Neuroinflamm 2017;4; \\ DOI 10.1212/NXI.0000000000000362}

This information is current as of June 14, 2017

\section{Updated Information \& Services \\ Supplementary Material}

References

Citations

Subspecialty Collections

Permissions \& Licensing

Reprints including high resolution figures, can be found at: http://nn.neurology.org/content/4/4/e362.full.html

Supplementary material can be found at: http://nn.neurology.org/content/suppl/2017/06/28/4.4.e362.DC1

This article cites 38 articles, 8 of which you can access for free at: http://nn.neurology.org/content/4/4/e362.full.html\#\#ref-list-1

This article has been cited by 2 HighWire-hosted articles: http://nn.neurology.org/content/4/4/e362.full.html\#\#otherarticles

This article, along with others on similar topics, appears in the following collection(s):

All Immunology

http://nn.neurology.org//cgi/collection/all_immunology Multiple sclerosis

http://nn.neurology.org//cgi/collection/multiple_sclerosis

Information about reproducing this article in parts (figures,tables) or in its entirety can be found online at:

http://nn.neurology.org/misc/about.xhtml\#permissions

Information about ordering reprints can be found online: http://nn.neurology.org/misc/addir.xhtml\#reprintsus

Neurol Neuroimmunol Neuroinflamm is an official journal of the American Academy of Neurology.

Published since April 2014, it is an open-access, online-only, continuous publication journal. Copyright Copyright (C) 2017 The Author(s). Published by Wolters Kluwer Health, Inc. on behalf of the American Academy of Neurology.. All rights reserved. Online ISSN: 2332-7812.

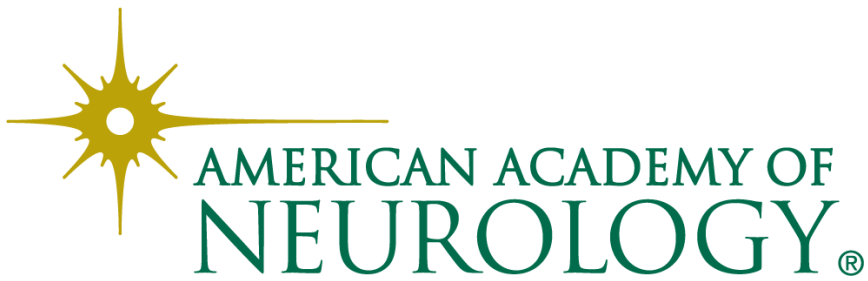

